\title{
Physical Growth and Echocardiographic Findings in Children with Down Syndrome
}

\author{
Sudigdo Sastroasmoro, Mathilda Y. Inkiriwang, Bambang Madiyono, \\ Ismet $\mathrm{N}$ Oesman
}

(Department of Child Health, Medical School, University of Indonesia, Jakarta)

\begin{abstract}
We compared the physical growth, nutritional status, and echocardiographic findings in children aged 3-7 years with Down syndrome who had no congenital heart disease. Thirty such patients who consecutively referred to the Division of Cardiology, Department of Child Health, Medical School, University of Indonesia / Cipto Mangunkusumo Hospital, Jakarta, were compared with sex and age matched controls consisted of normal children attending the Department. It appears that growth and nutritional status of children with Down syndrome tended to be retarded when compared to those of the controls. However, no significant difference were found on the M-mode echocardiographic values of the left ventricle, except that the left ventricular posterior wall thickness in study subjects was more that that of the controls. We concluded that althoughthe pulmonary architecture of patients with Down syndrome is thought to be less developed than that of normal children, it does not affect the left ventricular measurements and function as measured by M-mode echocardiography. [Paediatr Indones 1998; 38:54-61]
\end{abstract}

\section{Introduction}

Down syndrome is the most frequently found chromosomal abnormality; the incidence in general population is estimated to be 1 in every 1000 live births, being higher as the mother's age increases. ${ }^{1.4}$ This syndrome is known to be associated with congenital heart disease, especially atrioventricular septal defect. The incidence of congenital heart disease in Down syndrome is between 40 to $50 \%$, and 40 to $50 \%$ of the congenital heart disease is atrioventricular defect, either complete or incomplete

Author's address: Sudigdo Sastroasmoro, MD. Department of Child Health, Medical School, University of Indonesia, Jalan Salemba 6, Jakarta 10430, Indonesia. Tel, 62-21-3155742, Fax 3907743 
form. ${ }^{5-7}$ Congenital heart disease in children with Down syndrome is believed to have a different natural history than that in non-Down syndrome patients. Down syndrome patients with atrioventricular septal defect or ventricular septal defect may develop pulmonary hypertension in earlier age than non-Down syndrome patients with the same cardiac defect. ${ }^{8}$ Furthermore, there is evidence that the pulmonary architecture in patients with Down syndrome is similar to that of fetal pulmonary vasculature. ${ }^{9}$ On the other hand, few data are available on the cardiovascular status of Down syndrome patients who have no congenital heart disease. This study aimed to compare echocardiographic values of Down syndrome patents with no congenital heart disease to those of normal children. In addition, the physical growth and nutritional status of those patients were also examined.

\section{Methods}

This was a cross sectional study to compare the nutritional status and some cardiovascular aspects of Down syndrome patients without congenital heart disease with their age and sex matched normal children. This study was conducted entirely in Cipto Mangunkusumo Hospital, Jakarta. Subjects were included in the study if the following criteria were met: (1) Down's syndrome patients confurmed by chromosomal analysis, either of the primary, translocation, or mosaic type; ${ }^{10}(2)$ age between 3 to 7 years; (3) birth weight more than $3 \mathrm{~kg}$. Subjects who had congenital heart disease and those with other surgical problems, or those whose parents disagree to participate in the study were excluded. For controls, sex and age matched healthy children were recruited from attendants of the Outpatient Clinic of the Department of Child Health, Cipto Mangunkusumo Hospital, Jakarta. Sample size was estimated by using formula for paired t-test, giving the number of 30 subjects per group.

Data collected from all patients were body height and weight, chest X-ray in anteroposterior position, and two-dimensional and M-mode echocardiography. Chromosomal analysis was performed in the Department of Biology, Medical School, University of Indonesia, Jakarta, by using modified van Himmel method, ${ }^{11}$

Chest X-ray, and echocardiographic examinations were performed in blinded manner; i.e., the examiner was not aware whether a subject had Down syndrome or not. The following measurements were performed:

1 Chest X-ray: Cardio-thoracic ratio (CTR) was calculated according to standard procedure. $^{12}$

2 Echocardiography. Complete two-dimensional echocardiography and Doppler study were performed two exclude the presence of congenital heart disease. M-mode echocardiography was then performed. Measurements included left ventricular internal dimension in systole and in diastole with its respective shortening fraction, left ventricular posterior wall thickness in systole and in diastole with its thickening 
fraction, and interventricular septal thickness in diastole and in systole with its thickening fraction. All measurements were performed according to standard procedure. $^{13}$

Data were managed by using Epi-Info Program v 5.0. Hypothesis testing was performed using paired t-test for numeric data and McNemar test for nominal data; $95 \%$ confidence intervals were supplied whenever appropriate. Error protection for statistical tests was alpha 0.05 , and the statistical power was 0.80 .

\section{Results and Discussion}

Thirty sex and age-matched subjects were available for the study. Table 1 depicts the distribution of subjects' characteristics according to sex and age. The largest proportion was subjects of age 3 years, i.e. 11 subjects. Choice of subjects between 3 and 7 years was primarily based on practical purposes, i.e., in that age period the child has been able to be measured his or her height with a good precision, and also because wost Down syndrome patients in our clinic were of those age groups.

Table 1. Age and sex distribution of patients with Down syndrome

\begin{tabular}{cccc}
\hline \multirow{2}{*}{$\begin{array}{c}\text { Age } \\
(\mathrm{yr})\end{array}$} & \multicolumn{2}{c}{ Sex } & Total \\
\cline { 2 - 3 } & Male & Female & \\
\hline 3 & 6 & 5 & 11 \\
4 & 5 & 1 & 6 \\
5 & 3 & 3 & 6 \\
6 & 3 & 4 & 7 \\
\hline Total & 17 & 13 & 30 \\
\hline
\end{tabular}

Comparison of height of subjects with Down syndrome and controls can be seen in Table 2. Although no statistical analysis was done, it appears that there was clinically important difference between the mean height of subjects in both groups in subjects less than 5 years of age. To our surprise, in older subjects (5 years or more), the height difference between Down syndrome patients and that of controls is negligible. This finding is different with the report of $\mathrm{Berg}^{14}$ who noted significant difference in all age group. We have no explanation for this findings. 
Tabel 2. Means of height of subjects with and without Down syndrome by age

\begin{tabular}{cccccc}
\hline \multirow{2}{*}{$\begin{array}{c}\text { Age } \\
(\mathrm{yr})\end{array}$} & $\mathrm{n}$ & \multicolumn{4}{c}{ Height $(\mathrm{cm})$} \\
\cline { 3 - 6 } & & \multicolumn{2}{c}{ Down syndrome (SD) } & \multicolumn{2}{c}{ Control (SD) } \\
\cline { 3 - 6 } & & Mean & SD & Mean & SD \\
\hline 3 & 11 & 84.3 & 3.79 & 93.6 & 4.77 \\
4 & 6 & 88.2 & 9.33 & 97.0 & 3.29 \\
5 & 6 & 96.8 & 2.64 & 98.3 & 6.77 \\
6 & 7 & 106.0 & 6.59 & 105.9 & 5.61 \\
\hline
\end{tabular}

The weight of subjects of both groups were seen in Table 3. Due to limited subjects, no attempt was made to statistically analyze the data; however it appears that children with Down syndrome had on the average weighed $10 \%$ lower than controls. This finding is also consistent with that of Berg. ${ }^{14}$

Table 3. Means of body weight of subjects with and without Down syndrome by age

\begin{tabular}{cccccc}
\hline \multirow{2}{*}{ Age $(\mathrm{yr})$} & $\mathrm{n}$ & \multicolumn{4}{c}{ Weight $(\mathrm{kg})$} \\
\cline { 3 - 6 } & & \multicolumn{2}{c}{ Down syndrome } & \multicolumn{2}{c}{ Control } \\
\cline { 3 - 6 } & & Mean & SD & Mean & SD \\
\hline 3 & 11 & 10.5 & 1.97 & 12.2 & 1.97 \\
4 & 6 & 11.6 & 3.28 & 13.4 & 1.28 \\
5 & 6 & 13.3 & 1.73 & 15.7 & 1.51 \\
6 & 7 & 16.5 & 3.04 & 18.6 & 3.99 \\
\hline
\end{tabular}

The growth status, as represented by height/ge by using NCHS standard, was compared between subjects with or without Down syndrome. Normal growth status was noted in 11 out of 30 subjects with Down syndrome and 24 out of 30 normal subjects. McNemar test shows that the difference was statistically significant. This finding is similar to that reported by Berg. ${ }^{14}$ Referring to Table 2 , most of the difference must be attributed to subjects aged 4 years or less, since the older children of both groups had practically similar height. 
Table 4. Growth status according to height/age (NCHS) in subjects with Down syndrome controls

\begin{tabular}{ccccc}
\hline & & \multicolumn{3}{c}{ Control } \\
\cline { 3 - 5 } & Normal & 8 & Abnormal & Total \\
\hline \multirow{2}{*}{ Down } & Abnormal & 16 & 3 & 11 \\
syndrome & Total & 24 & 3 & 19 \\
& \multicolumn{2}{c}{$\mathrm{X}^{2}$ (Mc Nemar $)=7.798 ; \mathrm{p}<0.05$}
\end{tabular}

Similarly, when the nutritional status, as represented by weight/age by using NCHS standard, was compared between the 2 groups, it appears that children with Down syndrome had a lower level of nutritional status (Table 5). This was in accord with the previous report, that patients with Down syndrome tend to have a lower level of nutritional status than normal children. ${ }^{14.15}$

Tabel 5. The nutritional status according to hight/age (NCHS) in Down syndrome dan controls

\begin{tabular}{ccccc}
\hline & & \multicolumn{3}{c}{ Control } \\
\cline { 3 - 5 } & & Well-nourished & Under-nourished & Total \\
\hline \multirow{2}{*}{ Down } & Well-nourished & 9 & 2 & 11 \\
syndrome & Under-nourished & 11 & 8 & 19 \\
& Total & 20 & 10 & 30 \\
\hline
\end{tabular}

$\times 2$ (Mc Nemar) $=4.9 ; p<0.05$

Data of left ventricular dimensions and its shortening fraction is seen in Table 6. It appears that the left ventricular internal dimensions in systole and in diastole were not significantly difference between subjects with or without Down syndrome. Similarly, the shortening fraction was not significantly difference between the 2 groups. It means that systolic function in Down syndrome does not differ with that in normal children. It also means that pulmonary vasculature in Down syndrome that is believed to be different to that in normal children does not affect the cardiac function. These findings were in general consistent with the findings of Sugiyama et al. ${ }^{8}$ Sugiyama ${ }^{8}$ also found that the diastolic function in Down syndrome patients without congenital heart disease is depressed. We did not analyze the diastolic function. 
Tabel 6. Left ventricular dimensions and their shortening fraction in subjects with or without Down syndrome

\begin{tabular}{cccccccc}
\hline Kelompok & $n$ & \multicolumn{2}{c}{$\operatorname{LVID}_{\mathrm{ED}}(\mathrm{mm})$} & \multicolumn{2}{c}{$\mathrm{LVID}_{\mathrm{ES}}(\mathrm{mm})$} & \multicolumn{2}{c}{$\mathrm{SF}(\%)$} \\
\cline { 3 - 8 } & & Mean & $\mathrm{SD}$ & Mean & SD & Mean & $\mathrm{SD}$ \\
\hline SD & 27 & 30.8 & 8.4 & 21.7 & 6.3 & 36.3 & 8.4 \\
Kontrol & 27 & 34.6 & 12.2 & 24.2 & 8.6 & 32.4 & 5.5 \\
\hline \multicolumn{6}{c}{$\mathrm{c} p=0.08$} & $\mathrm{p}=0.07$ & \multicolumn{2}{c}{$\mathrm{p}=0.07$} \\
\hline
\end{tabular}

$\mathrm{LVID}_{\mathrm{ED}}=$ left ventricular internal dimension in end-diastole; $\mathrm{LVID}_{\mathrm{ES}}=$ left ventricular intemal dimension in end-systole; SF = shortening fraction

Tabel 7. Means of left ventricular posterior wall and interventricular septal thickness with their respective thickening fraction in subjects with or without Down syndrome

\begin{tabular}{|c|c|c|c|c|}
\hline & & Down syndrome & Control & Hypothesis testing \\
\hline \multirow[t]{2}{*}{$\mathrm{LVPW}_{\mathrm{ED}}, \mathrm{mm}$} & Mean & 4.1 & 4.2 & $p>0.05$ \\
\hline & SD & 0.8 & 1.2 & \\
\hline \multirow[t]{2}{*}{$\mathrm{LVPW}_{\mathrm{ES}}, \mathrm{mm}$} & Mean & 5.4 & 6.3 & $p>0.05$ \\
\hline & SD & 1.4 & 2 & \\
\hline \multirow[t]{2}{*}{ TFV, $\%$} & Mean & 34.2 & 38.2 & $p>0.05$ \\
\hline & SD & 4.2 & 6.4 & \\
\hline \multirow[t]{2}{*}{${ } \mathrm{VS}_{\mathrm{ED}}, \mathrm{mm}$} & Mean & 6.2 & 4.0 & $p<0.05$ \\
\hline & SD & 1.2 & 1 & \\
\hline \multirow[t]{2}{*}{$\mathrm{IVS}_{\mathrm{ES}}, \mathrm{mm}$} & Mean & 8.7 & 6.4 & $p>0.05$ \\
\hline & SD & 1.7 & 1.4 & \\
\hline \multirow[t]{2}{*}{$\mathrm{TF}_{\mathrm{s}}, \%$} & Mean & 28.1 & 33.2 & $p>0.05$ \\
\hline & SD & 5.4 & 6.3 & \\
\hline
\end{tabular}

$\mathrm{LVPW}_{\mathrm{ED}}=$ left ventricular posterior wall in end-diastole; $\mathrm{LVPW}_{\mathrm{ES}}=$ left ventricular posterior wall in end-systole; $T F V=$ thickening fraction of ventricular wall; $\mathrm{TF}_{\mathrm{ES}}=$ interventricular septum thickness in end-systole; IVS $_{E \mathrm{D}}=$ interventricular septal thickness in end-diastole; TFS = septal thickening fraction. 
The means of septal and posterior wall thickness with their respective thickening fractions were depicted in Table 7. All measured and calculated values, but the interventricular septal dimension in diastole, were within normal limits and no clinical or statistical difference was noted between patients with Down syndrome and controls. These findings are similar to that reported previously ${ }^{8}$ and probably means that pulmonary vasculature in Down syndrome that is believed to be different to that in normal children does not interfere with septal and left ventncular wall thickness.

To sum up, we have compared the nutritional status and echocardiographic findings in children aged 3 to 7 years with Down syndrome but without cardiac malformation with sex and age matched normal control. Patients with Down syndrome tend to be shorter and less well-nourished with the controls, but they have normal systolic function as measured by M-mode echocardiography. This demonstrates that the so called immature lung development in Down syndrome does not affect the heart in general.

\section{References}

1. Hook EB, Lindsjo A. Down syndrome in live births by a single-year matemal age interval in Swedish study: comparison with results from a New York study. Am J Hum Genet 1978; 30:19-27.

2. Kadri N, Siregar SP, Surachman HS, Monintja HE. Umur ibu sebagai faktor nisiko kelahiran bayi mongoloid di Rumah Sakat Cipto Mangunkusumo, Jakarta, 1975-1979. Maj Obstet Ginekol Indones 1982; 8:147-54.

3. Mikkelsen M. Down's syndrome. Current stage of cytogenetic research. Hum Genet 1971; 12:1-12.

4. Lindsten J. Marsk L. Berlind KS, et al, Incidence of Down's syndrome in Sweden during the years 1968-1977. In: Burgio R, Trisomy 21. Hum Genet (Suppl 2) 1981; 195-210.

5. Spicer RL. Cardiovascular disease in Down's syndrome. Pediatr Clin North Am 1984; 31:1331-43.

6. Rowe RD, Uchida IA. Cardiac malformation in mongolism. Am J Med 1961; 31:726-35.

7. Tandon R, Edwards JE. Cardiac malformation associated with Down's syndrome. Circulation $1973 ; 47: 1349-55$.

8. Sugiyama H. Property of myocardium in Down syndrome without congenital heart disease. J Japan Pediats 1991;1340-5.

9. Cooney TP, Thurlbeck WM. Pulmonary hypoplasia in Down's syndrome. N Engl J Med 1982; 307:1170-3.

10. Hook EB. Down syndrome. Frequency in human population and factors pertinent to variation in rates. In de la Cruz G. Trisomy 21 (Down syndrome). Baltimore: University Park Press, 1981;8-67.

11. Ramelan W. Personal communication. 
12. Caffey's pediatric X-ray diagnosis: an integrated imaging approach. 9th ed. St Louis: Mosby; 1993.

13. Roelandt JRTC, Sutherland GR, Iliceto S, Linker DT, Cardiac ultrasound. Edinburgh: Churchill Livingstone; 1993.

14. Berg JM, Crome L, France NE. Congenital cardiac malformation in mongolism. Brit Heart J 1960; 22:331-46.

15. Anneren G, Gustavson KH, Sara VR. Growth retardation in Down's syndrome with special reference to somatomedin. The 7th Congress of IAASSMD. New Delhi, India, 24-28 March 1985. 